\title{
Radium in the Healing Arts and in Industry
}

\author{
By JAMES G. TERRILL, JR., C.E., M.B., SAMUel C. INGRAHAM II, M.D., M.P.H., \\ and DADE W. MOELLER, M.S.
}

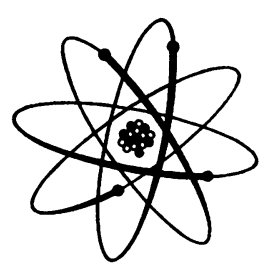

Radium is a naturally occurring radioactive element, widely distributed in minute but measurable concentrations throughout the world. For example, a gram of typical granite contains about $10^{-12} \mathrm{gm}$., or $10^{-12}$ curie, of radium (in popular usage, 1 curie of radium is 1 gram). Ocean bottom sediments may contain as much as $22 \times 10^{-12} \mathrm{gm}$. of radium per 1-gm. sample (1). The incrustations around certain natural springs may contain many times these amounts. At Saratoga Springs, N. Y., one deposit has been found to contain $769 \times 10^{-12} \mathrm{gm}$. of radium per gram of solid (1). The waters from these springs are radioactive. Mammoth Hot Springs in Yellowstone National Park, Wyo., contains 1,440× $10^{-12} \mathrm{gm}$. of radium (radium-equivalent) per liter; Curie Spring at Boulder, Colo., contains $267,800 \times 10^{-12} \mathrm{gm}$. of radium (radium-equivalent) per liter.

Some $4.5 \times 10^{-17}$ percent by weight of natural dry air is the radioactive gas radon, the first decay product of radium. This is a minute concentration, but the air in many of the radium-bearing mines in the western section of the United States contains appreciably heavier concentrations of radon.

Radium can be a public health problem both

Mr. Terrill is acting chief of the Radiological Health Branch, Division of Engineering Resources, Bureau of State Services, Public Health Service. Dr. Ingraham is assistant chief of the branch, and Mr. Moeller is an environmental radiation specialist on the staff. as it exists in nature and after it has been refined or concentrated. Refined radium has found widespread use in medicine and industry. Applications include the use of radium in medical therapy, industrial radiography, and luminous compounds. Reviewed here are some of the aspects of the public health problems associated with radium. These data supplement earlier presentations by the authors on the principal sources of radiation exposure in the United States (2, 3).

\section{Health Hazards}

Radium can be a source of internal or external exposure.

\section{Internal Exposure}

Internal exposure can occur as a result of ingestion of radium-containing substances or as a result of inhalation of radium particles or dust, the latter being more hazardous than the former. Approximately 100 microcuries (100 micrograms) administered orally or 20 microcuries intravenously or by inhalation would deposit about 1 microcurie of "fixed" radium in the body. The classic method for calculating the amount of radium in the body is based on determinations of the radon content of the air expired by the individual. A radon concentration of 1 micromicrocurie per liter of expired air is considered to correspond to a body content of about 0.1 microcurie of radium (4).

Body tolerances to radium vary widely. Generally, 1 to 10 microcuries of radium fixed in the skeleton will cause chronic radium poisoning; 10 to 100 microcuries will cause acute poisoning (5). However, fatal cases have been observed 
in which the radium burden of the body was as small as 1 microcurie (6).

The International Commission on Radiological Protection has accepted certain health standards for radium. For occupational workers, the maximum permissible amount fixed in the body is 0.1 microcurie. For radium appearing in the atmosphere as a soluble aerosol, the maximum permissible concentration is $8 \times 10^{-12}$ microcurie per milliliter. The maximum permissible concentration for radium in drinking water is $4 \times 10^{-8}$ microcurie per milliliter (y).

Radium compounds and products containing radium are all sources of radon. If inhaled or ingested, this gas is also a source of internal exposure. The generally maximum permissible concentration for radon in the air is $\mathbf{1 0}$ micromicrocuries per liter $\left(10^{-8}\right.$ microcuries per milliliter) (4).

\section{External Exposure}

External exposure may occur as a result of the beta and gamma radiations emitted by radium and its decay products. The alpha radiation of the energy emitted does not penetrate the normal (intact) skin and constitutes no external hazard. The beta and the gamma radiations, however, can penetrate the skin and are therefore externally hazardous. The maximum permissible weekly whole body exposure for occupational workers is 0.3 roentgen measured in air. The roentgen is the unit for measuring radiation absorption. (The milliroentgen is one one-thousandth of a roentgen.)

\section{Radioactive Nostrums}

Radium-bearing spring waters have been advertised for many years for their curative properties. Recently, advertisements of several radium-uranium-bearing mines in the western portion of the United States have implied relief or cure of a host of chronic diseases.

The curative claims for radioactive spring waters were investigated exhaustively during the 1920's and early 1930's. The medical and biological literature of that time is replete with articles on the effects of radioactive substances both in disease treatment (particularly of the chronic diseases) and in the healthy human body.
The early reports praised the medical effects of bathing in, ingestion of, and injection of radioactive materials. It may be inferred today, however, that the beneficial effects of such treatment, if any, were produced by psychosomatic processes. As experience was gained, evidence accumulated of delayed injuries and deaths from medically potent quantities of radioactive substances retained in the body (8). The consequent advice against indiscriminate use of radium, radon, and other radioactive medicaments applies not only to radioactive springs and radioactive mines but also to injections and oral dosage.

Pending the growth of understanding and precise evaluation of the probable hazards and benefits, current, approved medical practice is to use radioactive materials only under carefully controlled conditions, such as are found in a radiological clinic or radiologist's office. It is accepted that even such benefits as occur from the physical effects of radium are a result of the destruction of living tissues. The health profession believes that unnecessary exposure to the radioactivity in spring waters or in mines presents a needless radiation hazard to health.

\section{Refined Radium}

The entire world supply of refined radium amounts to about 5 pounds (approximately $2,500 \mathrm{gm}$. or 2,500 curies). It has been estimated that the amount in medical and industrial use in the United States is about 1,000 curies. Refined radium can be purchased on the open market. No formal application or special facilities are required for obtaining this material.

Radium, as normally used in medical therapy and industrial radiography, is enclosed in a capsule of platinum or silver approximately 0.5 mm. thick. The capsule acts as a container for the radon produced as well as an absorber for the alpha and beta radiations. The $0.5-\mathrm{mm}$. thickness of platinum or silver is sufficient to filter out all the alpha and beta radiations. The gamma radiation from 1 curie of radium, in equilibrium with its decay products and so enclosed, produces an exposure rate of approximately 9 roentgens per hour at a distance of 1 foot. If the radium is in a small capsule and 
if one considers only distances great in comparison to the size of the capsule, the radium, for practical purposes, represents a point source, and roentgen dosages at other distances can be calculated by the inverse square law. (Dosage is inversely proportional to the square of the distance.)

\section{Medical Therapy}

More than 80,000 radium treatments are given annually in the hospitals in the United States. A medium-sized modern hospital usually has about 300 millicuries (300 mg.) of radium on hand for this purpose. Practicing physicians using radium will often have 25 to 50 millicuries, and nearly every dermatologist has 10 millicuries or more on hand.

Sealed sources of radium are used for both external and internal therapy. External therapy (the source of radiation being outside the body) is accomplished by means of radium "packs," plaques, and moulages, molds for accurately positioning the source of radiation (contact therapy) and by radium "bombs" (teletherapy). Internal therapy is accomplished by inserting radium needles or radon seeds directly into diseased tissues (interstitial) or into body cavities (intracavitary) (9). Internal therapy probably represents the more common medical use of radium today.

Unsealed sources (radon ointments) are also in use but are still in the process of medical evaluation. Formerly, radium was administered by mouth and by vein for the treatment of certain diseases, but, as pointed out earlier, this use of radium has been abandoned as ineffective and dangerous.

\section{Exposure of Patients}

The usual medical patient undergoing radium therapy will receive large doses of radiation to selected limited portions of his body. These exposures are planned, controlled exposures to relieve disease conditions. Although they may injure nondiseased tissues also, they are administered for the net medical benefit of the patient. The net possible gain to the patient's health is assumed to justify the calculated risk of controlled exposure.

When radium is used externally, it may be compared somewhat to supervoltage X-ray. Dosages are similar (approximately 6,000 to 7,000 roentgens), but the radium sources commonly used normally require much more time than does X-ray to give doses of this magnitude.

Internal therapy dosages range from 1,000 to 10,000 roentgens. For example, the dose for cancer of the uterine cervix is approximately 4,000 roentgens. In any volume of tissue implanted with radon seeds or radium needles, the intensity distribution of the radiation varies considerably. Directly at the surface of the needle the dose rate is high, but it falls off rapidly at distances of a few millimeters. Since it is usually desired to eradicate all cells in the particular tissue being irradiated, the cells receiving the minimum dose constitute the critical therapy areas. Radiation exposures must be such as to insure a lethal dose to these cells $(9)$.

Utmost care should be exercised in the medical use of radium to prevent unnecessary injury to the patient. Such injury can result through the introduction of radon-leaking radium needles into the patient or the application of superficial radium sources with improper filtration (4).

\section{Exposure of Other Persons}

In the medical use of radium (or radon), nurses, technicians, therapists, radiologists, stenographers, and other persons (including other patients) who are in the vicinity of the radiation source or the patient are potentially exposed. These exposures may occur as a result of improper storage of the radiation source; during preparation of the source for therapy; during the application, insertion, or removal of the source from the patient; and during the period the patient is actually being treated.

In a survey of hospitals reported upon in 1941, Cowie and Scheele (10) found that improper storage of radium was common. Stenographers often worked within 5 to 6 feet of such sources.

The assembly or preparation of applicators is a task often assigned to residents, interns, technicians, and nurses. Cowie and Scheele 
(10) found that these people frequently had little knowledge of the dangers of the overexposure and occasionally had too little direct supervision. Measurements of the exposures received in selected cases during assembly of tandems under varying circumstances for intrauterine insertion showed body exposures ranging from 0.02 to 0.08 roentgen and exposures to the fingers reaching as high as 36 roentgens.

Technicians and therapists often receive exposures since radium seldom can be applied to the patient with accuracy, using remote handling devices. Local exposure to the hands in many cases exceeds 1 roentgen per day. This work should be rotated among qualified persons to reduce cumulative exposures of individual workers.

Nonpatient exposures in the United States are probably of the same order of magnitude as those reported in England. Parker (4) reports that the average daily exposure received by radium therapists in a typical teleradium installation in England in 1940 was between 0.13 and 0.25 roentgen. He also reports that the common practice in radium institutions has resulted in daily general body exposures of about 0.14 roentgen. It is important to note, however, that these exposures were obtained under conditions in which 0.2 roentgen per day was accepted as the maximum permissible exposure. More recent data tend to indicate lower exposures. Howarth and associates (11) report that the total body exposure for one radiologist routinely using radium in England was less than 0.01 roentgen ( 10 milliroentgens) per day. However, radiation received by the hands was approximately 0.15 roentgen per day and that of the fingers even higher.

Medical personnel and others can be exposed also after the radium has been applied to the patient. Therefore, it may be advisable to have patients undergoing treatment located in separate rooms or at least at a safe distance from other patients and in areas not frequented by medical and other personnel.

\section{Industrial Radiography}

Radium is used in industrial radiography for the nondestructive inspection of castings and weld products. In 1948, approximately $50 \mathrm{gm}$.
(50 curies) were being used for this purpose in the United States. During World War II, this figure reached $100 \mathrm{gm}$. (12) largely because $\mathrm{X}$-ray units were difficult to obtain. At present, much of the radium radiographic work done during the war has been discontinued, and either X-ray machines or cobalt-60 is used instead.

As a general practice, industrial concerns using radium for radiography rent their sources from commercial suppliers. From 80 to 90 percent of the industrial users follow this practice, whereas 90 percent of the medical users own their own sources (12). The industrial radioactive source is usually radium sulfate in a hermetically sealed silver capsule. This is supplied to the user in a steel or aluminum cartridge similar in appearance to a plumb bob. Radium sources are available in 25-, 50-, 100-, 200-, 300-, and 500-mg. units. The 100- and 200-mg. sources are used most commonly (12).

The fact that radium sources are small and portable accentuates the necessity for careful control of the source as a protection to persons uninformed of the health hazards associated with exposure to ionizing radiations. According to Williams (12): "The greatest problem in handling radium for industrial uses, based on our experience, comes from handling of the source by unauthorized persons. There have been several cases reported where a radium source has been handled by persons ignorant of its nature with resulting burns. Any user of radium should exercise extraordinary precautions to control it at all times."

Since the radium salt is sealed in a relatively thick metal capsule, gamma rays constitute the only radiation from the source. The major exposure to operators comes from handling the source during preparation for the photograph and returning it to its lead-shielded container after completion of the photograph (12). In some instances-where the source must be transported through ship double-bottoms, for example-overexposure seems unavoidable. Rotation of personnel and monitoring are indicated in these instances.

Many of the known overexposures in industry have resulted from improper indoctrination and supervision of personnel. Uninstructed 
workers tend to linger in areas of relatively high exposure because of ignorance about radiation health hazards and inadequate monitoring data. One relatively common error in industrial radiographic technique is the use of an actual radiation source in a trial, or "dummy" run, when a replica of the source would serve the purpose.

The trend in industry is toward larger radium sources. As a result, the areas used for industrial radiography in many industries are often inadequately shielded for the size of the source being used. Furthermore, radiographic areas are often placed adjacent to the radiographic darkrooms, offices, and washrooms, which should be free of radiation exposure.

Other hazards associated with the use of sealed sources of radium, in either medical therapy or radiography, are: (a) possibility of dropping, stepping on, or otherwise breaking the seal with resulting scattering of radium about an area and into the ventilation system (13), and (b) exposure to radon gas when initially opening the lead-shielded container of a source which has a break in its seal and has not been used for some time.

\section{Luminous Compounds}

Another important industrial use of radium is in luminous compounds. These substances, also known as luminous materials or radium paints, are a mixture of phosphorescent zinc sulfide and radium (not to be confused with nonradioactive fluorescent pigments which glow only under stimulus of light), mesothorium, and other similar radioactive substances. The material is usually packed in small glass bottles holding $1 \mathrm{gm}$. of the mixture. It is used to make markings that are visible in the dark by virtue of the light emitted by the zinc sulfide under bombardment from the radium. This compound is mixed with an adhesive to form a "paint" just before its actual application. The quantity of radium used is relatively small, ranging from 4 to 100 micrograms per gram of paint. The brightness required determines the amount of radium used (12).

During the 1940's, there were several thousand workers involved in the use of selfluminous paints in the United States (12). It is probable that a similar number of people are engaged in this work today.

Self-luminous instrument and watch dials are the main products of this industry, but hands and pointer also are painted. During World War II, such objects as vehicle markers (40 micrograms of radium per gram of paint), personnel markers (11 micrograms per gram), and luminous rope (5 micrograms per gram) were produced (12). Several hundred grams of radium were used in this industry during World War II.

Although individual workers handle relatively small quantities of radium at a time, the hazards to health from this use of radium are significantly greater because the radium is not sealed in a container, and, therefore, can be ingested or inhaled and retained in the body. The radium found in the bodies of workers actively engaged in this trade apparently consists of two fractions: a fixed fraction deposited in the bones, and a mobile fraction that is continually being excreted and replenished from recurrent contact with the radioactive luminous compound. When the workers are removed from their source of exposure, they usually excrete enough radium to lower the body content measurably.

\section{Hazards of Compounds}

Typical hazards associated with the handling of radium luminous compounds are: $(a)$ ingestion or inhalation of solid radioactive luminous compounds; $(b)$ inhalation of radon liberated from the compounds into the air; and (c) exposure of whole body to gamma radiation.

The first of these represents the greatest health hazard. Under the best working conditions existing in 1943 in the radium-dial-painting industry, about 15 percent of the workers accumulated more than 0.1 microcurie (the maximum permissible amount) of radium in their bodies (4). Substantially all dial painters, inspectors, and assemblers ingest or inhale a sizable fraction of the maximum permissible amount. In one survey it was reported that 30 percent of the workers employed for less than 1 year and 60 percent of all others showed radon breath samples above the maximum permissible level (4).

It has also been demonstrated that people 
working in the vicinity of radium-dial painters may accumulate an appreciable fraction of the maximum permissible dose in the body, despite the fact that they never actually handle radioactive materials. Such exposure is due to airborne transport of dispersed radioactive particles, dusts, and/or gases.

Inhalation of radon liberated from the compound into the air is the next most important health hazard associated with luminous compounds. To meet the requirements of the standard for the maximum permissible concentration of radon in air (10 micromicrocuries per liter or $10^{-8}$ microcuries per cubic centimeter), both workrooms and rooms in which the painted products are stored must be ventilated properly.

Evans (5) has pointed out that in the absence of ventilation, the storage of a few thousand dials in a moderate-sized room can raise the value of the radon concentration in the air to more than maximum permissible concentration in less than 1 hour. The radon content of the air in properly ventilated workrooms is about 30 percent or less of the maximum permissible - level (5).

Willard (14) has reported findings in a plant using the screen (stencil type) method of radium-dial painting. The concentration of radon in the workroom air was almost 200 percent of the accepted maximum permissible limit.

In dial painting and storage, the gamma radiation hazard should be slight. However, values as high as 0.05 to 0.10 roentgen per day have been observed in dial-painting plants where inadequate attention is paid to preventing the accumulation of paint supplies and finished work. In addition, in some plants gamma radiation hazards may arise from radium compound spilled on the floor, in cracks, in corners, and around pipes (5).

To protect dial painters, maximum amounts of radium luminous compound permitted in each painter's booth have been set. These are aimed at a radiation dosage of less than 0.02 roentgen per day for each worker. However, the usual exposure appears to be about 0.02 roentgen per day (4).

In considering internal and external exposure, it is important to recognize that the two are additive. To estimate total dosage the ex- ternal exposure of the whole body to gamma radiation from radium must be added to the internal exposure to the body tissues received by workers who have inhaled or ingested radium or radium compounds. For example, if an individual worker receives the maximum permissible external exposure and, in addition, has inhaled or ingested the maximum permissible concentration, his total exposure is twice the maximum permissible. The additive nature of external and internal exposures is further justification for limiting the quantity of radium handled by the individual worker and for insisting on adequate ventilation of the working space.

\section{Hazards of Finished Products}

Exposures may also occur in the use of the finished product to which a luminous compound has been added. A watch may have approximately 1 microgram of radium on it, and some clocks and aircraft instruments may contain from 10 to 100 micrograms. Evans (15) measured the gamma-radiation intensity in the cockpits of several large passenger airplanes and found 10 milliroentgens per hour at the gyro (compass) and generally over the surface of the entire instrument panel, 5 milliroentgens per hour at the pilot's ankles, 2 milliroentgens per hour at the pilot's elbow, and 1 milliroentgen per hour at the back of the pilot's seat, due to radium paint on the instruments.

\section{Other Sources of Exposure}

Exposure to radium and its decay products occurs in mining uranium, radium, vanadium, and other radioactive ores. Several thousand miners and millers are engaged in uranium mining and milling, which is carried on primarily in the plateau region of Colorado. The Public Health Service and several State health agencies active in studies of the specific hazards in this industry have reported finding radon exposures above the maximum permissible concentration in several of the mines. In these instances, control measures, particularly ventilation, are being applied as rapidly as possible. Detailed physical examinations of more than 1,100 workers are reported as re- 
vealing no evidence of health damage from radioactivity.

The operation of radon plants, commercially or in hospitals, can be hazardous to health since the worker may be exposed not only to radon but also to the alpha, beta, and gamma radiations of the radium and its other decay products. Both internal and external exposure hazards are present in a radon plant.

Exposures occur in industries which reprocess used radium sources or recover radium from used equipment. This reprocessing, performed by relatively few companies, involves hazards similar to those met in the operation of a radon plant. A radon concentration of 220 times the maximum permissible has been quoted as average for the air in the general laboratory of one of these companies (4).

There are also exposures in industries which use radium in the manufacture of static eliminators, electronic tubes, and radium and neutron sources. In general, published data on the numbers and exposures of personnel working in these industries are limited. Data on exposures resulting from the use of static eliminators, however, are available. A summary of these data are presented in the report entitled "Radiation Exposure in the United StatesStatic Eliminators," available from the radiological health branch, Bureau of State Services, Public Health Service.

Exposure can occur during the handling and shipping of radium. Excluding the radon hazard which exists if the radium is unsealed, these health hazards are similar to those encountered with other beta- and gamma-emitting radioactive isotopes (3).

Numerous instances of radium being lost have been reported. Taft (16) has reported on 107 losses, 59 of which were recovered completely, 11 partially recovered, 36 completely lost, and 1 not recorded. There is danger of radiation exposure in all such occurrences.

\section{Summary}

Radium, a radioactive element, can be a health problem as it is found in nature, as it is processed, or as it is used in its refined state. Although the health problems of radium were recognized somewhat tardily, experience with radium has contributed much to modern radiological health protection programs.

Today, exposure to radium sources potentially affects many individuals. In medicine, in addition to the patients undergoing treatment, these individuals include nurses, technicians, therapists, radiologists, dermatologists, and others who handle or prepare radium. Stenographers and other persons who work in the vicinity of the radiation source or patients being treated are also possibly subject to chronic exposure.

Industry was using 50 curies of radium in radiography in 1948. Several hundred curies were utilized in the luminous compound industry during World War II. Exposures to radium occur also in the mining and processing of radioactive ores; in the manufacture of items containing radium such as static eliminators, electronic tubes, and radium and neutron sources; and in industries which reprocess used radium sources or recover radium from used equipment. Radium losses and spills, which occur despite the most conscientious handling, produce other sources of exposure. Additional, but needless, exposures occur in the use of radium-bearing mines and springs for alleged "medical treatments."

Radium can be purchased on the open market. No formal application or special facilities are required. Currently, a total of about 1,000 curies are in medical and industrial use in the United States.

Sound radiological practice suggests that official health agencies should learn where radium sources are used in their communities and should assure themselves that proper precautionary measures are maintained.

\section{REFERENCES}

(1) Pitzer, E. C.: Disposal of radioactive wastes. Report No. KAPL-703. Schenectady, N. Y., General Electric Co., Knolls Atomic Power Laboratory, Nov. 1, 1951.

(2) Moeller, D. W., Terrill, J. G., Jr., and Ingraham, S. C., II : Radiation exposure in the United States. Pub. Health Rep. 68: 57-65 (1953).

(3) Ingraham, S. C., II, Terrill, J. G., Jr., and Moeller, D. W.: Reactor-produced radioactive isotopes. Pub. Health Rep. 68: 609-615 (1953).

(4) Parker, H. M.: Health-physics, instrumentation, and radiation protection. In Advances in biological and medical physics, edited by J. H. 
Lawrence and J. G. Hamilton. New York, Academic Press, 1948, vol. I, pp. 223-285.

(5) Evans, R. D.: Protection of radium dial workers and radiologists from injury by radium. J. Ind. Hyg. \& Toxicol. 25 : 253-269 (1943).

(6) Aub, J. C., Evans, R. D., Hempelmann, L. H., and Martland, H. S.: The late effects of internally deposited radioactive materials in man. Medicine 31: 221-329 (September 1952).

(y) U. S. National Bureau of Standards: Recommendations of the International Commission on Radiological Protection and of the International Commission on Radiological Units. Handbook 47. Washington, D. C., U. S. Government Printing Office, June 29, 1951.

(8) Erans, R. D.: Radium poisoning. A review of present knowledge. Am. J. Pub. Health 23: 1017-1023 (1933).

(9) Quimby, E. H.: Radiation therapy: Tissue dosage of roentgen rays and gamma rays. In Medical physics, edited by Otto Glasser. Chicago, the Year Book Publishers, 1950, vol. I, pp. 1165-1180.
(10) Cowie, D. B., and Scheele, L. A.: A survey or radiation protection in hospitals. J. Nat. Cancer Inst. 1: 767-787 (1941).

(11) Howarth, J. L., Miller, H., and Walter, J.: Some measurements of gamma ray dose received by a radiotherapist during radium operations. Brit. J. Radiol. 23: 245-255 (1950).

(12) Williams, C. R.: Radiation hazards in industry. J. Indust. Hyg. \& Toxicol. 30: 294-299 (1948).

(13) Saenger, E. L., Gallaghar, R. G., Anthony, D. S., and Valaer, P. J.: Emergency measures and precautions in radium accidents. J. A. M. A. 149: 813-815 (1952).

(14) Willard, F. J., Jr.: Radium dial painting control methods. Indust. Med. 15: 170-172 (1946).

(15) Evans, R. D.: Physical biological administrative problems associated with the transportation of radioactive substances. Nuclear Science Series Publication No. 205, preliminary report No. 11. Washington, D. C., National Research Council, 1951.

(16) Taft, R. H.: Radium lost and found. Charleston, S. C., John J. Furlong and Sons, 1938.

\section{Radioactive Steroids Available to Researchers}

Qualified investigators may obtain free of charge limited supplies of radioactive steroids by addressing their requests in the form of a letter concisely describing the proposed research to the Endocrinology Study Section, Division of Research Grants, National Institutes of Health, Public Health Service, Bethesda 14, Md.

Available are cortisone acetate (compound E), hydrocortisone (compound $\mathrm{F}$ ), corticosterone (compound $\mathrm{B}$ ), and five other radioactive steroids which were obtained as intermediates in the synthesis of the cortisone acetate. These compounds are all labeled at position 4 with $\mathrm{C}^{14}$ and have a specific activity of $0.49 \mathrm{mc} . / \mathrm{m}$. mole, except the corticosterone, which has a specific activity of $1.47 \mathrm{mc} . / \mathrm{m}$. mole.

Transfer and use of these materials are subject to current Atomic Energy Commission regulations. The compounds are made available through funds supplied by the Public Health Service's National Institute of Arthritis and Metabolic Diseases. Synthesis of these ringlabeled compounds was an international effort, in which several commercial laboratories and members of the Endocrinology Study Section have participated. The above-named radioactive steroids have already been distributed by the study section to 24 laboratories, 2 of which are in England. Many of the investigators using these materials are leaders in the field of medical research, particularly endocrinological medical research. 